\title{
O padRÃo de CARREIRA POLÍtICA dos DEPUTADOS FEDERAIS DA ARENA BAIANA: TRAJETÓRIAS ESTÁVEIS E LEALDADES PESSOAI ${ }^{1}$
}

\author{
Rafael Machado Madeira \\ Mestre e doutorando em Ciência Política pela \\ Universidade Federal do Rio Grande do Sul
}

Email: madeirar@bol.com.br

\section{Resumo}

O presente artigo visa analisar o grau de coesão partidária da ARENA baiana tendo como fio condutor o exame dos padrões de carreiras políticas dos deputados federais do partido eleitos sob o bipartidarismo. Para mensurar o grau de coesão, tomar-se-ão como variáveis dados referentes às trajetórias partidárias dos parlamentares. Assim, aspectos como o número de migrações partidárias, o tempo de filiação anterior à conquista de um mandato na Câmara dos Deputados e o número de cargos e de mandatos ocupados, serão tomados como parâmetro para a análise. Por fim, pretender-se-á explicar, por exemplo, a fragmentação da estrutura interna e dos quadros da ARENA baiana e o conseqüente fracasso eleitoral do seu sucessor - PDS - a partir da Nova República através da trajetória política de suas principais lideranças remanescentes da legenda governista.

Palavras-chave: partidos políticos; autoritarismo; democracia.

${ }^{1} \mathrm{O}$ presente artigo é em uma versão modificada de "A ARENA baiana: trajetórias estáveis e lealdades pessoais", capítulo da dissertação de mestrado intitulada "ARENA ou ARENAs? A coesão partidária da legenda do regime em três estados brasileiros", defendida junto ao Programa de Pós-Graduação em Ciência Política da Universidade Federal do Rio Grande do Sul em abril de 2002. 
análise de partidos e sistemas partidários é um filão da Ciência

Política que vem se destacando no conjunto da disciplina, sobretudo a partir da década de 1990. Estudos como os de Fleischer (1981), Lima júnior (1997), Meneguello (1998), Figueiredo e Limongi (1999), Power (2000), Santos (2001) e Rodrigues (2002) constituem-se exemplos do esforço que vem sendo feito visando a uma maior compreensão do sistema político-partidário em nosso país. Inserindo-se nesta perspectiva, o presente artigo tem como objetivo abordar um tema que ainda não foi suficientemente trabalhado ${ }^{2}$, qual seja, a configuração da legenda partidária encarregada de apoiar o regime militar brasileiro.

Assim, o presente artigo busca examinar o partido do regime naquilo que se acredita ter sido ele de fundamental importância para os desdobramentos que foram verificados após a volta do multipartidarismo no país. Em virtude do fato da ARENA ser a grande matriz a partir da qual boa parte dos quadros dos partidos atualmente considerados como conservadores teve sua iniciação política, acredita-se que a análise das trajetórias político-partidárias destas elites torna-se um relevante locus para um maior aprofundamento do debate acadêmico acerca deste tema ${ }^{3}$. Com relação à escolha do estado a ser analisado, pode-se salientar o fato do impacto desta "herança arenista" ter sido relevante na Bahia, onde se constata uma significativa predominância dos remanescentes da ARENA em nível estadual. Além disso, o estado é um dos mais importantes da federação e, particularmente, da região Nordeste.

A análise tem, portanto, como objetivo principal o exame dos dados referentes à trajetória política dos parlamentares eleitos pela ARENA baiana nas quatro legislaturas empossadas ao longo do período bipartidário. Tal estudo parte da premissa de que o exame dos

${ }^{2} \mathrm{O}$ único trabalho encontrado que tem na ARENA o seu objeto principal de análise é o estudo de Jenks (1979). Além deste, Mainwuaring, Meneguello e Power (2000) também analisam esta questão, embora de forma bastante rápida. Cabe salientar que análises como as de Reis (1978), Kinzo (1988) e Melhem (1998), que examinam, respectivamente, o sistema bipartidário, o MDB nacional e o MDB-PMDB paulista, fazem referência direta ao período aqui examinado.

${ }^{3}$ Algumas iniciativas neste sentido podem ser destacadas, como a de Rodrigues (2002) e a de Power (2000). 
diferentes padrões de carreira política põe-se como um relevante caminho para um maior entendimento tanto do atual sistema partidário como de suas configurações particulares nas diferentes unidades da federação (LIMA JÚNIOR, 1997; SANTOS, 2001).

Tal análise tomará como principais variáveis para o estudo aspectos como filiações anteriores, tempo de filiação antes da conquista do primeiro mandato de deputado federal e mandatos, cargos e funções de liderança no interior dos partidos, ocupados por cada parlamentar. Identificando não só a origem partidária, mas a experiência prévia destes parlamentares e o tempo de sua convivência (isto é, a experiência político-partidária compartilhada) entre os demais parlamentares, pretende-se mensurar o peso e a correlação de forças entre as antigas organizações partidárias (período pré-64) no interior da ARENA baiana. O quadro a seguir sistematiza e ajuda a estabelecer, de forma mais clara, as relações entre tais variáveis, bem como a sua relevância para a presente análise.

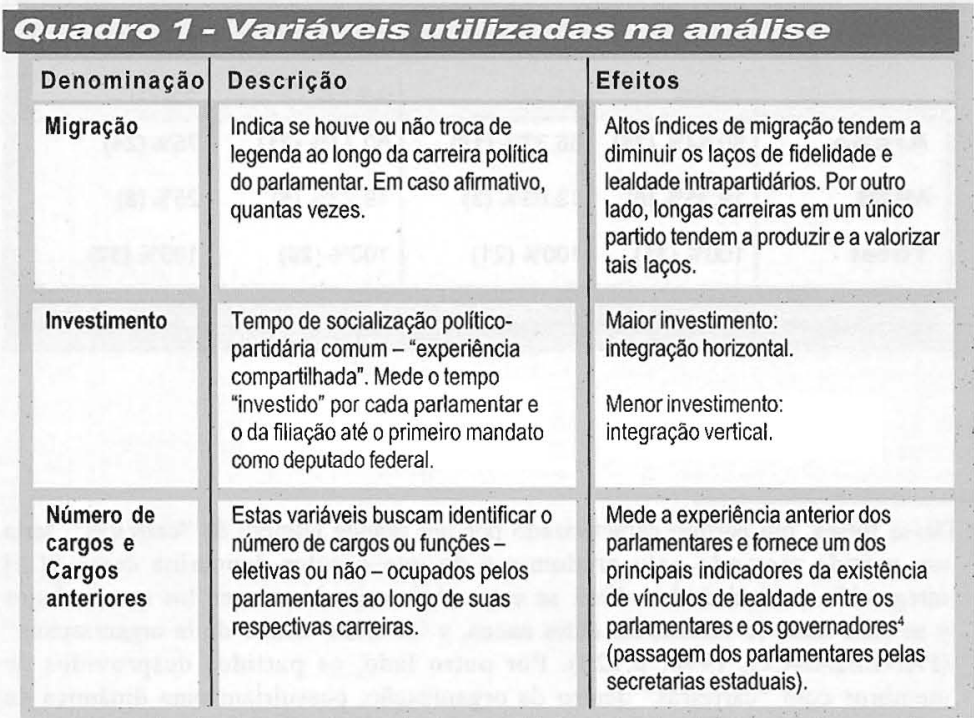

${ }^{4}$ Para uma discussão acerca do papel exercido pelos ex-governadores enquanto agentes polarizadores da política baiana (MADEIRA, 2002). 
Como pode ser observado no quadro, para o exame destes padrões de carreiras políticas utilizar-se-ão os conceitos de integração vertical e integração horizontal cunhados por Panebianco (1990). De acordo com o autor, integração vertical ilustra a situação em que o ingresso na organização se dá nos níveis mais baixos da hierarquia partidária para, com base em um longo e constante aprendizado, ascender até os postos de comando mais altos no interior do mesmo. Por outro lado, integração horizontal delimita situações em que o ingresso no partido pode dar-se diretamente nos níveis mais altos da hierarquia, a partir, por exemplo, da conversão de capitais de outras esferas na esfera política ${ }^{5}$.

Antes, porém, convém examinar os dados referentes à composição das bancadas partidárias da ARENA e do MDB ao longo do período, para se ter uma noção mais precisa do peso de cada legenda nas bancadas federais baianas.

\section{tabala 1}

Representação partidária na Câmara dos Deputados, BA - 1966/1978

\begin{tabular}{l|l|l|l|l|} 
& 1966 & 1970 & 1974 & 1978 \\
\hline Arena & $80,64 \%(25)$ & $86,37 \%(19)$ & $80,77 \%(21)$ & $75 \%(24)$ \\
MDB & $19,35 \%(6)$ & $13,63 \%(3)$ & $19,23 \%(5)$ & $25 \%(8)$ \\
Total & $100 \%(31)$ & $100 \%(21)$ & $100 \%(26)$ & $100 \%(32)$
\end{tabular}

Fonte: Sampaio (1967/1968) e Guimarães (1981).

${ }^{5}$ Dessa forma, um partido caracterizado por um grande número de "carreiras", seria um partido marcado pelo predomínio do que o autor denomina como "[...] integración vertical de las elites: se entra en la organización en los niveles bajos y se sube hasta le vértice; las elites nacen, y 'se crían' dentro de la organización." (PANEBIANCO, 1990, p.128). Por outro lado, os partidos desprovidos de membros com "carreiras" dentro da organização, possuiriam uma dinâmica de recrutamento denominada pelo autor como integração horizontal, graças a qual "se entra en lo partido en los niveles altos, a partir de ámbitos exteriores en los cuales se detenta ya una posición de preeminencia; es decir, se convierten en recursos políticos, recursos de otro tipo" (PANEBIANCO, 1990, p.128). 
Ao se examinar a proporção de arenistas e emedebistas eleitos para a Câmara dos Deputados, o aspecto que mais chama a atenção é o claro predomínio dos primeiros nas quatro legislaturas. Vários fatores ajudam a explicar tal predomínio da ARENA no estado: em primeiro lugar, pode-se citar a importância, para os partidos políticos baianos, do acesso à máquina governista estadual (SAMPAIO, 1998). Dessa forma, o fato de os arenistas já estarem no governo (Lomanto Júnior) e permanecerem nele durante todo o período favoreceu enormemente o êxito dos candidatos do partido, que podiam contar com as vantagens das máquinas estadual e federal para se beneficiarem eleitoralmente, ajudando a garantir o êxito da ARENA em eleger, no mínimo, três quartos das bancadas baianas na Câmara dos Deputados.

Um segundo aspecto é o fato de estarem na ARENA praticamente todas as principais lideranças políticas baianas. $\mathrm{O}$ fato de se encontrarem nas suas hostes lideranças como os ex-governadores Juraci Magalhães (UDN), Luís Viana Filho (PL) e Lomanto Júnior (PLPTB), bem como outras lideranças fortes como o "eterno" deputado federal Manoel Novaes (PR), e lideranças então ascendentes, como o deputado federal Antônio Carlos Magalhães (UDN) e do deputado Oliveira Brito, que capitaneou a ala arenista do PSD, ajudou a assegurar ao partido uma hegemonia política sem possibilidade de contestação por parte do MDB no estado. Ao analisar o pleito de 1966 e a importância destas lideranças, que ocupavam um papel central na política baiana, Sampaio (1968) afirma:

A ação de personalidades politicamente poderosas funcionou, assim, como um substituto do pluripartidarismo, sob a capa do sistema de dois partidos. Não faltou quem comentasse, com razão, que o pleito se decidiu pela atuação de uma meia dúzia de grandes eleitores. Conseguir a indicação de um deles era a melhor garantia de uma candidatura (SAMPAIO, 1968, p.131).

Pode-se afirmar que estes dois aspectos valem não só para este pleito, mas para todos os que ocorreram ao longo do período examinado. Esses aspectos que tenderiam sempre a um fortalecimento recíproco: a posse do governo favorece a ascensão e a manutenção das lideranças do partido, e o apoio destas lideranças, por sua vez, garante a manutenção do desempenho eleitoral do mesmo. A im- 
portância crucial tanto do controle da máquina estatal quanto da presença destas lideranças no partido ajuda a entender, por exemplo, por que o desempenho surpreendente do MDB nas eleições de 1974 em outros estados da federação não se verifica na Bahia (onde é eleito um dos poucos senadores arenistas).

Porém, mesmo estando o poder estando basicamente nas mãos de algumas lideranças e sendo preponderantemente indiferenciado entre os partidos o seu caráter no que diz respeito à composição de seus quadros ${ }^{6}$, é possível identificar a importância da cor partidária, principalmente ao se analisar o papel da dinâmica local na definição das escolhas eleitorais e na definição da filiação aos dois partidos recém-criados. Apesar de o caráter governista ser historicamente atribuído pela literatura especializada a todos os partidos baianos, o fato de este espaço (no partido governista) ter sido ocupado pela UDN, PR, PL e PTB não deixa outra alternativa para a grande maioria dos pessedistas senão ingressarem no partido oposicionista, mesmo com todas as dificuldades que esta escolha certamente traria (e trouxe) a seus integrantes.

Cabe salientar aqui este aspecto curioso que é o fato de que, diferentemente dos demais estados ${ }^{7}$ - em que a tendência era de o PTB ocupar o papel de oposição e da UDN e do PSD o papel de apoio ao novo regime - entre os deputados federais baianos, a maioria dos que se filiaram ao MDB provinha do PSD e não do PTB. A hipótese aqui levantada para explicar - ao menos em parte - tal fato baseia-se na existência de um acordo eleitoral estabelecido entre as principais lideranças da UDN, do PTB e do PL já nas eleições para o governo do estado em 1962. Para uma explicação mais conclusiva tal aspecto mereceria um estudo mais detido, o que não foi realizado por não ser este o foco central do presente artigo.

\section{Tabela?}

Filiação aos antigos partidos: ARENA - BA

\begin{tabular}{c|c|c|c|c|c|c|c|c|c|c|c|c|c|c|c|c|c|c} 
& PIB & MIR & PSB & PIN & PSP & PDC & PSD & PST & PR & PRP & PRT & UDN & PL & Arena & MDB & NF* & Total \\
66 & 1 & - & - & - & - & - & 1 & 1 & 4 & 2 & - & 11 & - & 2 & 1 & 2 & 25 \\
70 & 2 & - & - & - & - & - & 2 & - & 3 & 1 & - & 6 & - & 4 & - & 1 & 19 \\
74 & 2 & - & - & - & - & 1 & 2 & 1 & 2 & - & - & 6 & - & 5 & - & 2 & 21 \\
78 & 1 & - & - & - & - & 1 & 2 & 1 & 2 & 1 & - & 6 & - & 7 & - & 3 & 24
\end{tabular}

Fonte: Abreu et al. (2001) 
A partir desta primeira aproximação com os dados, pode-se identificar, no conjunto das bancadas eleitas pela ARENA baiana, um claro predomínio tanto dos udenistas quanto dos puros 8 . Por ser a UDN o principal partido da base de sustentação do governo estadual, na ocasião liderado por figuras como Juracy Magalhães e Luis Viana Filho, coube aos remanescentes da UDN baiana a parte do leão no interior da nova legenda governista. Tais características permitem já de início identificar este partido como a principal "escola" dos deputados federais arenistas eleitos por este estado.

\section{Pássaros fora do ninho? A presença de dois ex-petebistas e de um ex-emedebista na Arena baiana}

Com relação à presença, aparentemente contraditória, de expetebistas no interior das bancadas federais arenistas, pode-se afirmar que $o$ fato deste partido ter feito parte das negociações que acabaram por eleger sob a sua legenda o ex-liberal Lomanto Júnior ao governo estadual abriu as portas da ARENA aos trabalhistas baianos que preferiram ficar nas hostes do partido governista. Cabe, assim, perguntar até que ponto a presença destes parlamentares nas bancadas federais arenistas representa uma contradição.

6 "Fora da caracterização de partido do governo e partido da oposição, os matizes da ARENA e do MDB na Bahia praticamente não se distinguem. Apenas a coloração centrista é um pouco mais visível na ARENA, como o MDB ostenta maior dose de colorido populista e esquerdizante" (SAMPAIO, 1967/1968, p.122).

${ }^{7}$ Em Madeira (2002), esta mesma análise foi realizada tendo-se como objeto também os deputados federais arenistas dos estados do Rio Grande do Sul e São Paulo. Com relação a este aspecto em particular, verificou-se que a dinâmica eleitoral baiana no período multipartidário anterior caracterizava-se pela existência de uma nítida clivagem eleitoral entre as duas principais organizações partidárias no estado: UDN e PSD. Tal aspecto ajuda a explicar o acordo firmado em 1962 que viabilizou a candidatura de Lomanto Júnior ao governo do estado.

8 Por puros entendem-se aqui os parlamentares arenistas que não ocuparam cargos políticos no período multipartidário anterior. Isto é, aqueles parlamentares que não tiveram uma experiência política prévia à legenda governista. 


\section{Tabela 3}

Trajetória política dos deputados arenistas baianos, PTB - 1966

\begin{tabular}{l|l|l|l|c} 
Deputado & Migração & "Investimento" & $N^{0}$ cargos & Cargos anteriores \\
João Alves & Não & 8 anos & 1 & DF
\end{tabular}

Fonte: Abreu et al. (2001)

Em 1966, o único ex-petebista eleito pela ARENA baiana à Câmara dos Deputados é João Alves. Com relação à sua trajetória políti$\mathrm{ca}, \mathrm{o}$ aspecto mais marcante é a estabilidade de sua carreira, dado que o parlamentar se encontra presente em todas as legislaturas examinadas. Tendo iniciado sua carreira política como suplente na Assembléia Legislativa baiana em 1958, João Alves elege-se pela primeira vez deputado federal em 1962, pela Aliança Trabalhista, integrada pelo Partido Republicano (PR), pelo Partido de Representação Popular (PRP) e pelo PTB. Com a extinção dos antigos partidos, o parlamentar faz parte do grupo de trabalhistas que migra para as fileiras do partido governista, partido pelo qual se reelegeria em 1966, 1970, 1974 e 1978, filiando-se nessa última legislatura na qual o parlamentar, com o fim do bipartidarismo, filia-se ao PDS.

\section{TEbela 4}

Trajetória política dos deputados arenistas baianos, PTB - 1970/1974

\begin{tabular}{l|l|l|l|c} 
Deputado & Migração & "Investimento" & No cargos & Cargos anteriores \\
João Alves & Năo & $12 / 16$ anos & 1 & DF (2)/DF (3) \\
Lomanto Júnior & 1 & $24 / 28$ anos & $4 / 5$ & Ver, Pref (2), DE e Gov / DF
\end{tabular}

Os ex-petebistas eleitos em 1970 e 1974 possuíam trajetórias diferentes, o que havia em comum era a experiência em cargos políticos com a conquista dos mandatos nas bancadas baianas. Diferente-

${ }^{9}$ As abreviaturas utilizadas são: Ver: vereador; DE: deputado estadual; DF: deputado federal; Pref: prefeito; Gov: governador; Ass: assessor; Min: ministro; e Sec. Est: secretário estadual. 
mente de João Alves, Lomanto Júnior inicia sua carreira política no âmbito municipal, elegendo-se vereador e prefeito de seu município de origem, Jequié (BA), para somente após, tornar-se uma liderança política de âmbito estadual. Carreiras longas, uma marcada pela integração horizontal e outra pela integração vertical (Panebianco, 1990): este é o perfil dos ex-petebistas eleitos nas bancadas arenistas em 1974/78. Cabe, por fim, salientar que Lomanto Júnior construiu sua carreira no PL e não no PTB.

\section{Tabela 5}

Trajetória politica dos deputados arenistas baianos, PTB-1978

\begin{tabular}{l|l|l|l|c} 
Deputado & Migração & "Investimento" & $N^{0}$ cargos & Cargos anteriores \\
\hline João Alves & Não & 20 anos & 1 & DF (4)
\end{tabular}

Fonte: Abreu et al. (2001)

No que tange ao peso dos remanescentes do PTB nas bancadas federais, a presença de apenas dois parlamentares é, no mínimo, curiosa, portanto, com a instauração do bipartidarismo, grande parte da bancada federal do PTB baiano migrou para as fileiras do novo partido governista (MADEIRA, 2002). No entanto, pode-se observar que o ingresso da maioria dos parlamentares trabalhistas neste novo partido não se refletiu na presença destes nas bancadas arenistas baianas na Câmara dos Deputados. Este aspecto pode indicar uma certa dificuldade encontrada pelos ex-trabalhistas em conquistar espaço no interior da nova agremiação e de manter, após o ingresso na ARENA, o apoio eleitoral necessário para a manutenção de seus respectivos mandatos sob a nova legenda.

Sampaio, ao examinar a migração dos deputados estaduais baianos para os dois novos partidos em 1965, sugere uma explicação para tal processo, uma vez que a filiação dos parlamentares petebistas à ARENA foi total.

Ainda mais interessante é que nenhum petebista da Assembléia ingressou no MDB. A estranheza se desfaz se levarmos em 
conta que se trata de um PTB praticamente desaparecido então, de cunho puramente eleitoral e 'lomantista', ou seja, vinculado ao governador Lomanto Júnior, que a ele se filiou no pleito de 1962 (SAMPAIO, 1967-1968, p. 120).

Com relação ao segundo caso, a migração do ex-pessedista Oliveira Brito para a ARENA baiana é mais um indicador da ausência de outra alternativa à maioria das lideranças do PSD, senão a de se filiarem ao partido oposicionista, ainda mais porque eram enormes as dificuldades para manterem suas carreiras no interior do MDB baiano.

\section{Tabola 6}

Trajetória política dos deputados arenistas baianos, MDB-1966

\begin{tabular}{l|l|l|l|l} 
Deputado & Migração & "Investimento" & $\mathbf{N}^{\circ}$ cargos & Cargos anteriores \\
Oliveira Brito & 1 & 19 anos & 1 & DE, DF (4) e Min. (2)
\end{tabular}

Fonte: Abreuet al. (2001)

Além de ser um dos deputados federais mais experientes do PSD baiano, Oliveira Brito possuia uma trajetória marcada pela presença em dois ministérios do governo do petebista João Goulart (19611964). Tendo ocupado as pastas de Educação e Cultura e Minas e Energia (pasta que ocupou até a tomada do poder pelos militares), Oliveira Brito, acompanhando a maioria do PSD baiano, filia-se ao partido oposicionista com a instauração do bipartidarismo. No entanto, antes mesmo das eleições o parlamentar migra para a legenda arenista, partido pelo qual se elege em 1966. Essa razão, provavelmente, do seu envolvimento direto com o governo Goulart, este ex-emedebista teve o seu mandato cassado em setembro de 1969.

Considerando-se o caráter "lomantista" do PTB, a aliança formada pelo partido juntamente com a UDN, PR e PL para as eleições de 1962 , bem como o fato de parte significativa dos deputados federais e estaduais petebistas ter emigrado para a ARENA com a criação deste partido, pode-se afirmar que a presença de dois remanescentes deste 
partido nas bancadas federais arenistas não implica em uma contradição ao se levar em conta a dinâmica política própria deste estado. Já com relação à presença de Oliveira Brito, o fato de ele ter militado no PSD por no mínimo 19 anos, tendo vivenciado a rivalidade entre PSD e UDN em duas eleições estaduais e municipais e da grande maioria do seu partido ter migrado para o MDB (inclusive ele mesmo) permite caracterizá-lo como um "estranho no ninho" da ARENA baiana.

\section{Os puros na Bahia: divisão interna, experiência prévia e integração horizontal}

Debruçando-se sobre os puros, é possível constatar que o caso baiano situa-se em um nível intermediário entre o gaúcho e o paulista no que diz respeito ao peso deste grupo no interior das bancadas arenistas eleitas para a Câmara dos Deputados (MADEIRA, 2002). Aspecto facilmente identificado, uma vez que, apesar da existência destes parlamentares em todas as legislaturas, este grupo nunca ocupa (como nas bancadas paulistas) uma posição de destaque no conjunto dos parlamentares, salvo na última legislatura, na qual, apesar de constituir menos de um terço da bancada, este grupo é o que possui maior peso no interior da mesma, ultrapassando os ex-udenistas.

\section{Tabela 7}

Trajetória dos deputados arenistas baianos, ARENA-1966

\begin{tabular}{|c|c|c|c|c|}
\hline Deputado & Migração & "Investimento" & $\mathbf{N}^{0}$ cargos & Cargos anteriores \\
\hline Viana Neto & Não & Nenhum & Nenhum & Nenhum \\
\hline Luis Braga & Näo & 7 anos & 2 & Sec.Mun. e Sec.Est. \\
\hline
\end{tabular}

Apesar de integrarem a bancada arenista baiana desde a primeira legislatura aqui examinada, em 1966 este grupo conta com apenas dois representantes: Luis Vianna Neto e Luís Carlos Leal Braga. Em virtude de estes puros possuírem ligações diretas com duas das maiores lideranças arenistas (Luís Viana Filho e Antônio Lomanto Júnior), o 
fato de não terem sido filiados formalmente a nenhum partido político não implica, necessariamente, uma diminuição da coesão partidária desta bancada. A existência destes vínculos significativos (manifestado em um caso através do parentesco - essencial na política baiana - e em outro, por ter o parlamentar participado do primeiro escalão do governo municipal e estadual nas administrações de Lomanto Júnior) chama a atenção para o cuidado que se precisou ter ao classificá-los como puros, o que não significa que estes parlamentares não possam ter tido algum tipo de experiência e laços diretos com lideranças partidárias.

Mesmo não tendo sido eleito para nenhum cargo eletivo e não tendo sido encontrada nenhuma referência a uma possível filiação a algum partido durante o período multipartidário, Luís Braga atuou, em 1959-1960, como diretor de obras do município de Jequié (BA) e, em 1963-1964, como secretário interino de Agricultura; em ambos os casos, quem ocupava a chefia do Executivo era Antônio Lomanto Júnior. Isso explica o fato deste parlamentar caracterizar-se por possuir uma trajetória política de sete anos, apesar de não ser formalmente filiado a nenhum partido político antes da ARENA.

Após ter se filiado à ARENA, Luís Braga candidata-se e conquista o seu primeiro mandato de deputado federal. Alcançando a reeleição, a partir de 1971 o parlamentar ocupou a primeira vice-presidência da Câmara. Em 1974, candidata-se novamente, conquistando apenas uma suplência e deixando a Câmara dos Deputados em janeiro do ano seguinte.

\section{TEbola :}

Trajetória dos deputados arenistas baianos, ARENA-1970

\begin{tabular}{l|l|l|l|l} 
Deputado & Migração & "Investimento" & No cargos & Cargos anteriores \\
Luís Braga & Não & 11 anos & 3 & Sec Mun, Sec Est e DF \\
$\begin{array}{l}\text { Prisco Viana } \\
\text { Vasco Neto }\end{array}$ & Não & 3 anos & 1 & Sec Est \\
Ivo Braga & Não & 7 anos & Nenhum & Nenhum \\
\end{tabular}

Fonte: Abreu et al. (2001)

Após o pleito de 1970, apesar da saída de Luis Viana Neto, os puros passam a ocupar quatro cadeiras na Câmara dos Deputados. Este crescimento deve-se ao êxito eleitoral de Prisco Viana, Vasco Neto 
e Ivo Braga, juntamente com a permanência de Luís Braga, reeleito. Apesar de não terem sido filiados formalmente a nenhum partido político, os puros baianos eleitos em 1970 mantêm o perfil anterior, marcado pela passagem em postos de relevância no âmbito estadual, notadamente as secretarias estaduais.

A identificação da participação, por exemplo, de Luís Braga e Ivo Braga no secretariado de Lomanto Júnior (1963-1967) permite afirmar a existência de um maior envolvimento destes com o governador baiano. No entanto, esta vinculação a Lomanto Júnior não é garantia de que os mesmos também tenham sido filiados ao PTB, ou mesmo ao PL (antigo partido de Lomanto Júnior). Por esse aspecto, os mencionados parlamentares são classificados como puros, embora seja comprovada a participação dos mesmos em postos do primeiro escalão do governo estadual antes da criação da ARENA. Ainda com relação à eleição destes parlamentares, pode-se identificar a força da liderança do ex-governador que teve, no mínimo, três de seus ex-secretários estaduais eleitos para a Câmara dos Deputados.

\section{TEbela 9}

\section{Trajetória dos deputados arenistas baianos, ARENA- 1974}

\begin{tabular}{l|l|l|l|c} 
Deputado & Migração & "Investimento" & N $^{\circ}$ cargos & Cargos anteriores \\
Viana Neto & Não & 8 anos & 1 & DF \\
Prisco Viana & Não & 7 anos & 2 & Sec Est e DF \\
Vasco Neto & Não & 4 anos & 1 & DF \\
Rômulo Galvão & Não & 3 anos & 1 & Sec Est \\
Leur Lomanto & Não & 3 anos & 1 & Of. de Gab Min
\end{tabular}

Fonte: Abreu et al. (2001)

No pleito de 1974, além de Vianna Neto, Prisco Viana e Vasco Neto, reeleitos, surgem dois novos parlamentares que não haviam ocupado nenhum cargo eletivo antes do fim do período multipartidário: Rômulo Galvão e Leur Lomanto (filho do ex-governador Lomanto Júnior). Após três anos atuando, o primeiro como secretário estadual do então governador Antônio Carlos Magalhães e o segundo como oficial de gabinete do então ministro da Educa- 
ção e Cultura, Jarbas Passarinho, os novos puros eleitos em 1974 reelegem-se em 1978, legislatura na qual se filiam ao PDS, com a volta do multipartidarismo.

Analisando-se os puros eleitos em 1974, observa-se que, assim como na bancada anterior, os cinco parlamentares ocuparam funções de destaque ao longo do exercício de seus respectivos mandatos. O exame da trajetória destes parlamentares reforça o perfil identificado na legislatura anterior, de carreiras políticas caracterizadas pelo ingresso lateral, o que permite identificar na ARENA baiana uma dinâmica baseada preponderantemente na integração horizontal de seus deputados federais, principalmente ao se identificar que vários destes parlamentares ou eram parentes ou mantinham vínculos pessoais com as principais lideranças do partido no estado.

\section{Tabela 10}

Trajetória dos deputados arenistas baianos, ARENA-1978

\begin{tabular}{l|l|l|l|c} 
Deputado & Migração & "Investimento" & No cargos & Cargos anteriores \\
Leur Lomanto & Não & 7 anos & 2 & Of de Gab Min e DF \\
Prisco Viana & Não & 11 anos & 2 & Sec Est e DF (2) \\
Rômulo Galvão & Não & 7 anos & 2 & Sec Est e DF \\
José Amorim & Não & Nenhum & Nenhum & Nenhum \\
Ubaldo Dantas & Não & 3 anos & 1 & Sec Est \\
Stoesel Dourado & Não & 8 anos & 1 & DE (2) \\
Carlos Santana & Não & 4 anos & 2 & DE e Sec Est
\end{tabular}

Fonte: Abreu et al. (2001)

Finalmente, na bancada eleita em 1978, observa-se, novamente, o crescimento deste grupo, que pela primeira vez ultrapassa o número de ex-udenistas, tornando-se o mais numeroso no interior da bancada arenista baiana. Este crescimento pode ser explicado, pelo êxito em que se reelegeram Prisco Viana, Rômulo Galvão e Leur Lomanto, pelo fato de Vasco Neto (que conquistara apenas uma suplência) ter assumido uma cadeira, e, por fim, com a eleição de quatro estreantes na Casa: José Amorim, Ubaldo Dantas, Stoessel Dourado e Carlos Santana. Dessa 
forma, apesar de terem sido sete os puros a se elegerem diretamente (como indicado na tabela anterior), este grupo contou com oito membros ao longo da legislatura, uma vez que Vasco Neto, que havia alcançado somente uma suplência no pleito de 1978, assume uma cadeira na Câmara dos Deputados.

Mantendo-se o mesmo perfil, as trajetórias dos quatro novos puros caracterizam-se pela experiência prévia destes em cargos políti$\cos$, uma vez que três deles já haviam exercido alguma função anteriormente. Os dois maiores exemplos são Stoessel Dourado e Carlos Santana, ambos ex-deputados estaduais (Dourado eleito em 1970 e 1974 e Santana em 1974). Santana, além de ter sido deputado estadual, ocupou também a Secretaria Estadual de Educação e Cultura durante o governo Roberto Santos (1975-1979).

Além dos novatos, os veteranos eleitos em 1978 também contam com trajetórias prévias significativas. Este fato pode ser identificado já que Prisco Viana e Vasco Neto exercem então já o terceiro mandato de suas carreiras. Por sua vez, Leur Lomanto e Rômulo Galvão encontram-se no segundo mandato, além de já terem exercido outras funções antes da conquista do primeiro mandato na Câmara dos Deputados. Além disso, a experiência prévia de alguns dos estreantes (na Assembléia Legislativa e em secretarias estaduais) também contribui para neutralizar consideravelmente o impacto que este grupo, presumivelmente, teria na diminuição da coesão partidária da bancada eleita em 1978.

Cabe salientar ainda que o fato de ter sido possível identificar em praticamente todos os puros as alas às quais pertenciam e as lideranças às quais estavam vinculados permite afirmar que a presença destes parlamentares é um bom indicador das divisões internas do partido (entre suas lideranças) e do reflexo desta divisão no interior das bancadas. $\mathrm{O}$ fato de grande parte dos puros iniciar suas carreiras políticas como secretários estaduais ajuda a mensurar a importância das secretarias estaduais de governo para o ingresso na carreira política e como um "trampolim" para a Câmara dos Deputados na Bahia. Este aspecto comprova também a importância do controle do governo estadual para a manutenção das principais lideranças baianas, e de seus grupos, no interior do partido governista. 


\section{O núcleo duro do partido: a importância dos ex-udenistas na ARENA baiana}

Examinando-se o peso das demais organizações partidárias, um primeiro aspecto que chama a atenção é o número de ex-udenistas que formaram o grupo mais importante no interior das bancadas arenistas baianas. Representando quase a metade da bancada federal eleita neste estado em 1966, os remanescentes da UDN, apesar de sofrerem uma redução significativa já na segunda legislatura analisada, evidenciavam-se pela manutenção do número de cadeiras no restante do período. Dessa forma, os ex-udenistas caracterizam-se como o principal grupo no interior das bancadas federais arenistas ao longo do período em questão.

\section{TEbela I1}

Trajetória dos deputados arenistas baianos, UDN- 1966

\begin{tabular}{l|l|l|l|c} 
Deputado & Migração & "Investimento" & No cargos & Cargos anteriores \\
Rui Santos & Não & 21 anos & 2 & DF (5) e Sec Est \\
Oscar Cardoso & Não & 20 anos & 3 & Ver, DE (3) e DF \\
Vasco Filho & Não & 16 anos & 1 & DF (4) \\
Tourinho Dantas & Não & 16 anos & 2 & DE (3) e DF \\
Wilson Falcão & Não & 16 anos & 3 & Ver (2), DE e DF \\
Clodoaldo Costa & Não & 16 anos & 2 & Ver (2) e DE (2) \\
AC Magalhães & Não & 12 anos & 2 & DE DF (2) \\
Heitor Dias & Não & 12 anos & 3 & Ver, Pref e DF \\
Edvaldo Flores & Não & 12 anos & 2 & Pref e DF (2) \\
Hannequim Dantas & Não & 8 anos & 1 & DF (2) \\
Alves de Macedo & Não & 8 anos & 1 & DF (2)
\end{tabular}

Fonte: Abreu et al. (2001)

Em virtude do peso deste grupo, a sua presença pode ser tomada como uma manifestação da existência de um grau significativo de coesão no interior da bancada arenista baiana uma vez que identificase na UDN o principal lócus de recrutamento para os quadros arenistas que compõem as bancadas federais deste partido. Além disso, a conquista de três mandatos no Senado Federal e até mesmo a eleição (indireta) de um governador em duas ocasiões, todos provenientes da primeira bancada federal da ARENA baiana, comprovam que foi das 
fileiras da antiga UDN que saiu uma parcela considerável dos principais quadros da nova organização partidária.

Passando-se a examinar as trajetórias destes parlamentares, dos 11 ex-udenistas eleitos em 1966, destaca-se o fato de seis caracterizarem-se por estarem vinculados a este partido e exercendo cargos eletivos, pelo menos, desde 1950. Este aspecto, por implicar na existência de um longo tempo de socialização política dentro desta estrutura partidária, reforça ainda mais a caracterização da antiga UDN como a principal "escola" política dos quadros arenistas neste estado, e identifica no partido um padrão de carreiras baseado na longevidade e estabilidade de seus quadros partidários.

Além deste aspecto, dos 11 ex-udenistas, nada menos que nove começavam a exercer em 1966, no mínimo, o quarto mandato eletivo de suas carreiras; apenas um era estreante na Câmara dos Deputados. Isto é, além da existência de trajetórias caracterizadas pela longevidade e estabilidade no interior do partido, os remanescentes da UDN eleitos em 1966 caracterizavam-se por possuírem uma significativa experiência legislativa.

Por serem representativas do padrão de carreiras identificado entre os remanescentes da UDN baiana, serão aqui examinadas mais detidamente as trajetórias políticas de duas de suas lideranças: Rui Santos e Antônio Carlos Magalhães.

Após o fim do Estado Novo, Rui Santos elegeu-se deputado na Assembléia Nacional Constituinte, já pela legenda udenista. Após a promulgação da nova Carta, o parlamentar completou o mandato ordinário, reelegendo-se em 1950, pela Aliança Democrática (formada pela UDN, PR, PSB, PSP e o PDC). Paralelamente ao exercício do mandato, a partir de 1951, o parlamentar passou a integrar o diretório nacional da UDN. Conquistando o seu terceiro mandato consecutivo, Rui Santos foi escolhido para assumir a vice-liderança de seu partido na Câmara dos Deputados. Voltando a se eleger em 1958, entre abril de 1959 e julho de 1962, o parlamentar licencia-se da Casa para assumir a Secretaria de Governo do seu estado durante o mandato do também udenista Juraci Magalhães (1959-1963). Em 1962, Rui Santos conquista mais uma vez uma vaga na Câmara dos Deputados, tornando-se, a partir de 1964, vice-líder do seu partido. 
Filiando-se à ARENA, em março de 1966, o parlamentar assume a vice-liderança da nova organização e neste mesmo ano conquista o seu sexto mandato na Câmara dos Deputados. Dessa forma, Rui Santos é um dos parlamentares mais experientes da ARENA baiana nesta legislatura. Em 1970, elege-se senador, assim como o seu colega de bancada, o também ex-udenista Heitor Dias, deixando a Câmara em janeiro do ano seguinte.

Já Antônio Carlos Magalhães inicia a sua carreira política elegendo-se deputado estadual em 1954. Em seu único mandato no legislativo estadual, Magalhães já ocupou posições de destaque, como a liderança de seu partido na Casa e a presidência da Comissão de Finanças da Assembléia. Quatro anos depois, Antônio Carlos Magalhães conquista seu primeiro mandato na Câmara dos Deputados. Reeleito em 1962, o parlamentar participa (ao lado do deputado Pedro Aleixo, do senador Paulo Sarasate e do próprio Juraci Magalhães, entre outros) decisivamente das articulações visando à formação da ARENA. Logo após, torna-se o primeiro presidente do partido na Bahia.

Após conquistar o seu terceiro mandato em 1966, Antônio Carlos Magalhães assume, a partir de fevereiro do ano seguinte, a prefeitura de Salvador, a convite do então governador baiano Luís Viana Filho (1967-1971). E, em abril de 1970, reassume sua cadeira ao se descompatibilizar da prefeitura para poder disputar o governo do estado. Eleito, Antônio Carlos Magalhães assume o governo do estado da Bahia em março de 1971, deixando a Câmara dos Deputados. É a partir do seu primeiro governo estadual que Antônio Carlos Magalhães desvincula-se politicamente da influência de Juraci para se tornar uma liderança com luz própria.

\section{TEbola 12}

Trajetória dos deputados arenistas baianos, UDN-1970

\begin{tabular}{l|l|l|l|c} 
Deputado & Migração & "Investimento" & N $^{\circ}$ cargos & Cargos anteriores \\
Tourinho Dantas & Não & 20 anos & 2 & DE (3) e DF (2) \\
Wilson Falcão & Não & 20 anos & 3 & Ver (2), DEe DF (2) \\
Edvaldo Flores & Não & 16 anos & 2 & Prefe DF (3) \\
Hannequim Dantas & Não & 12 anos & 1 & DF (3) \\
Rui Bacelar & Não & 8 anos & 1 & Ver \\
Rogério Rego & Não & 11 anos & 1 & Ch Gab (2)
\end{tabular}

Fonte: Abreu et al. (2001) 
Em 1970, verifica-se uma diminuição de cinco cadeiras nos remanescentes da antiga UDN na bancada arenista baiana. Cabe ressaltar que esta redução não significa uma perda de espaço dos mesmos no interior da ARENA baiana, visto que a diminuição não é reflexo, unicamente, do fracasso eleitoral dos ex-udenistas no pleito de 1970.

Nesta eleição, dos sete parlamentares que tentaram a reeleição, quatro lograram êxito e três obtiveram uma suplência. Além destes, Vasco Filho não se candidata e, entre os demais, Antônio Carlos Magalhães elege-se governador e Rui Santos e Heitor Dias, senadores. Observa-se, então, que dos 10 parlamentares que se candidataram a algum cargo eletivo em 1970, sete lograram êxito e apenas três fracassaram. Dessa forma, ao contrário do que possa parecer em um primeiro momento, a significativa redução dos exudenistas na bancada arenista eleita em 1970 não pode ser interpretada como uma perda de espaço sofrida por este grupo dentro da ARENA baiana.

$\mathrm{O}$ fato dos ex-udenistas passarem a ocupar tanto o governo estadual como as duas vagas do estado no Senado Federal atestam a força e a importância dos remanescentes da UDN no interior do partido. Além disso, a presença de dois novos remanescentes da UDN na bancada eleita em 1970 é um indicador da capacidade deste grupo em manter o espaço conquistado no interior do partido.

Nesta legislatura, representando quase um terço dos deputados federais arenistas, com quatro parlamentares evidenciados por longas trajetórias dentro da antiga UDN e com apenas dois estreantes na Câmara (mesmo assim, ambos com uma experiência considerável na antiga UDN e na ARENA), este grupo constitui-se novamente o núcleo duro da bancada baiana, confirmando a posição da UDN como a "escola" política mais importante das bancadas arenistas no estado.

\section{Tabela 13}

Trajetória dos deputados arenistas baianos, UDN-1974

\begin{tabular}{l|l|l|l|c} 
Deputado & Migração & "Investimento" & $N^{\circ}$ cargos & Cargos anteriores \\
Wilson Falcão & Não & 24 anos & 3 & Ver (2), DE e DF (3) \\
Rogério Rego & Não & 15 anos & 2 & Ch Gab (2) e DF \\
Rui Bacelar & Não & 12 anos & 2 & Ver e DF \\
Vieira Lima & Não & 12 anos & 2 & Ver e DE \\
Jutai Magalhães & Nã̃o & 16 anos & 3 & Ver, DE e Vice Gov \\
João Durval & Não & 19 anos & 2 & Ver (2) e Pref
\end{tabular}

Fonte: Abreu et al. (2001) 
Na terceira legislatura, cinco dos seis parlamentares tentam garantir sua permanência na Câmara dos Deputados: Wilson Falcão, Edvaldo Flores, Tourinho Dantas, Rogério Rego e Rui Bacelar. No entanto, apenas Wilson Falcão, Rogério Rego e Rui Bacelar obtêm êxito na tentativa. Juntando-se a isso o fato de Hannequim Dantas não ter concorrido, nota-se nesta legislatura a presença de somente um dos 11 ex-udenistas eleitos oito anos antes. Aqui o fracasso eleitoral de dois dos cinco pretendentes à reeleição pode ser tomado como o primeiro revés eleitoral significativo sofrido pelos ex-udenistas nas eleições à Câmara dos Deputados.

No entanto, a eleição de Vieira Lima e Jutaí Magalhães, então deputados estaduais, e de João Durval, então prefeito de Feira de Santana (BA), que conquistam seus primeiros mandatos na Câmara dos Deputados em 1974, juntamente com a reeleição dos outros três parlamentares, resulta novamente na presença de seis ex-udenistas e na conseqüente manutenção deste grupo como a principal força no interior da bancada.

Além da manutenção das principais características identificadas nos ex-udenistas eleitos anteriormente, os remanescentes deste partido eleitos em 1974 caracterizam-se também por iniciarem suas carreiras políticas no legislativo municipal e, a partir daí, alcançarem postos de relevância estadual para depois chegar à Câmara dos Deputados. Aqui a importância das relações verticais de fidelidade também pode ser verificada nas trajetórias, por exemplo, de João Durval e Jutaí Magalhães.

Vinculado a Antônio Carlos Magalhães, João Durval, após eleger-se vereador em duas legislaturas consecutivas (1955-1963), candidata-se à Prefeitura Municipal de Feira de Santana (BA) em 1962, sendo derrotado pelo candidato do Partido Social Democrático (PSD). Após filiar-se à ARENA, o ex-vereador candidata-se novamente, conquistando a prefeitura do município em 1966. Três anos após deixar a prefeitura, João Durval candidata-se e conquista o seu primeiro mandato como deputado federal. Reeleito em 1978, Durval não chega a assumir o mandato, por ter sido nomeado para a Secretaria Estadual de Saneamento da Bahia durante o segundo governo do ex-udenista Antônio Carlos Magalhães. Em 1982, João Durval foi eleito governador do Estado, com o apoio decisivo de Antônio Carlos Magalhães. 
Iniciando-se na política como vereador, no município de Itarapica (BA) entre 1959 e 1963, Jutaí Magalhães, após ter ocupado a presidência desta Câmara Municipal, elege-se, em 1962, deputado estadual na legenda udenista. Nesta legislatura, além de se tornar líder do Bloco da Unidade Parlamentar, Jutaí é eleito presidente da Assembléia Legislativa entre 1965 e 1966 . Neste último ano, com o fim do multipartidarismo, o parlamentar filia-se à ARENA baiana. Na nova legenda, o então deputado estadual elege-se, em setembro de 1966, indiretamente, vice-governador do seu estado.

No pleito de 1970, Jutaí Magalhães torna-se novamente deputado estadual e, quatro anos depois, conquista, pela primeira vez, um mandato na Câmara dos Deputados, alcançando a maior votação no Estado para este posto. Eleito, por via indireta, senador por seu estado, Jutaí Magalhães deixa a Câmara dos Deputados no fim de seu mandato, em janeiro de 1979.

\section{Tabela 14}

Trajetória dos deputados arenistas baianos, UDN- 1978

\begin{tabular}{l|l|l|l|c} 
Deputado & Migração & "Investimento" & N $^{0}$ cargos & Cargos anteriores \\
Wilson Falcão & Năo & 28 anos & 3 & Ver (2), DE e DF (4) \\
Rogério Rego & Não & 19 anos & 2 & Ch Gab (2) e DF (2) \\
Rui Bacelar & Não & 16 anos & 2 & Ver e DF (2) \\
Vieira Lima & Não & 16 anos & 3 & Ver, DE e DF \\
Honorato Viana & Não & 33 anos & 3 & Pref, DE (5) e Sec Est \\
Francisco Benjamim & Não & 16 anos & 2 & DE (2), Sec Est
\end{tabular}

Fonte: Abreu et al. (2001)

Com a eleição de Jutaí Magalhães para o Senado, na última legislatura analisada, Wilson Falcão, em seu quinto mandato, Rogério Rego e Rui Bacelar, ambos no terceiro mandato, e Vieira Lima, no segundo mandato, reelegem-se para mais quatro anos na Câmara dos Deputados. Além destes, o surgimento de dois estreantes mantém a estabilidade no número de cadeiras conquistadas pelos ex-udenistas. São eles: Honorato Viana e Francisco Benjamim.

Honorato Viana, primo de Luís Viana Filho, foi prefeito nomeado do município baiano de Santo Amaro da Purificação em 1945 e caracte- 
riza-se por ter sido um dos fundadores da UDN no estado. Ao final de um longo período sem ocupar cargos eletivos, Honorato Viana elegese em 1958 deputado estadual pela legenda udenista. Reeleito em 1962, o parlamentar licencia-se do cargo para ocupar a Secretaria da Fazenda do estado durante o governo de Lomanto Júnior. Filiando-se à ARENA, o parlamentar conquista sucessivamente mais três mandatos na Assembléia Legislativa baiana (1966, 1970 e 1974), durante os quais assumiu a presidência da Casa por duas gestões (1968-1969 e 19751977). Em 1978, Honorato Viana elege-se deputado federal, exercendo o seu primeiro mandato na Câmara dos Deputados na última legislatura aqui examinada.

Em vista da importância dos cargos ocupados pelos exudenistas, pelo seu peso no interior das bancadas federais eleitas pela ARENA baiana e pela existência de trajetórias longas e estáveis que definem o perfil dos quadros remanescentes deste partido, pode-se concluir que este grupo contribui decisivamente para a existência de um grau significativo de coesão partidária nas bancadas federais arenistas baianas, além de permitir a caracterização deste grupo como o "núcleo duro" do partido governista no estado. Em virtude da maioria das lideranças arenistas ter saído deste partido, o mesmo é um espaço privilegiado para a análise da freqüência e valorização de laços verticais de lealdade característica da dinâmica política baiana.

\section{Estabilidade e experiência: a presença dos ex-perrepistas na ARENA baiana}

Entre os partidos políticos existentes no regime multipartidário anterior, o Partido Republicano (PR) forma-se como segundo partido com maior influência nas bancadas arenistas baianas. Diferentemente dos remanescentes da UDN, os perrepistas caracterizam-se pela alta estabilidade na manutenção de seus mandatos ao longo das legislaturas em questão. Este aspecto é facilmente identificado, já que são quatro os ex-perrepistas que se elegem em 1966, dois dos quais mantêm seus mandatos ao longo de todo o período analisado. 
TEbela 15

Trajetória dos deputados arenistas baianos, PR-1966

\begin{tabular}{l|l|l|l|c} 
Deputado & Migração & "Investimento" & No cargos & Cargos anteriores \\
Manoel Novais & 1 & 25 anos & 2 & Ch de Gab e DF (7) \\
Raimundo Brito & 1 & 24 anos & 2 & DE e DF (3) \\
Neci Novais & Não & 4 anos & 1 & DF \\
Teódulo de Albuquerque & 1 & 21 & 1 & DF (3)
\end{tabular}

Fonte: Abreu et al. (2001)

Com relação aos ex-perrepistas, pode-se observar que a grande experiência de seus membros na Câmara dos Deputados, adquirida ao longo tempo (no mínimo 10 anos) no exercício de cargos eletivos neste partido (a exceção fica por conta de Neci Novais), faz com que a presença dos mesmos também contribua para o aumento da coesão partidária das bancadas arenistas baianas. No entanto, cabe salientar que 0 fato de suas principais lideranças não terem iniciado neste partido suas trajetórias políticas, mas sim terem migrado para o mesmo ao longo de suas respectivas carreiras, não permite identificar o PR como a "escola" de formação política destes parlamentares.

Outro aspecto que chama a atenção é que a migração, por exemplo, de Manuel Novaes e Raimundo Brito (ambos provenientes da UDN) para o PR tenha sido provocada por disputas internas na antiga UDN que provocaram a saída de alguns udenistas. Sobre este ponto, além de possibilitar a ascensão como liderança estadual, a saída deste grupo do partido controlado por Juraci Magalhães permitiu que estes negociassem apoio parlamentar ao governo vencedor do pleito em 1950, Régis Pacheco (que havia derrotado Juraci), em troca de cargos no executivo estadual. Este aspecto não impediu o apoio dos perrepistas aos governos udenistas eleitos ao longo do período. Aqui se identifica, novamente, a importância do acesso à máquina governamental para a manutenção das lideranças políticas baianas.

Com relação às trajetórias dos ex-perrepistas, a mais longa é a de Raimundo Brito. Ex-deputado estadual (1923-1925 e 1934-1937), após o fim do Estado Novo, Brito elege-se deputado estadual, pela legenda udenista, em 1950. Logo após assumir o mandato, o parlamentar (um dos novaisistas) transfere-se para o PR, passando a ocupar a liderança de seu novo partido. Nesta legislatura, Raimundo Brito foi também 
líder do governo do então pessedista Régis Pacheco (1951-1955). Em 1954, o então deputado estadual elege-se pela primeira vez à Câmara dos Deputados, na legenda da Aliança Republicana Cristã, formada pelo PR e pelo Partido Democrata Cristão. Após reeleger-se em 1958 e 1962, o parlamentar filia-se em 1966 à ARENA baiana. Em sua nova legenda, Brito conquista o seu quinto mandato na Casa. Em janeiro de 1971, Raimundo Brito deixa a Câmara, sem ter tentado a reeleição.

\begin{tabular}{|c|c|c|c|c|}
\hline \multicolumn{5}{|l|}{ Tabela 16} \\
\hline \multicolumn{5}{|c|}{ Trajetória dos deputados arenistas baianos, PR- 1970} \\
\hline Deputado & Migração & "Investimento" & $\mathrm{N}^{0}$ cargos & Cargos anteriores \\
\hline $\begin{array}{l}\text { Manoel Novais } \\
\text { Neci Novais } \\
\text { Teódulo de Albuquerque }\end{array}$ & $\begin{array}{l}1 \\
\text { Não } \\
1\end{array}$ & \begin{tabular}{|l|}
29 anos \\
8 anos \\
25 anos
\end{tabular} & $\begin{array}{l}2 \\
1 \\
1\end{array}$ & $\begin{array}{c}\text { Ch de Gab e DF (8) } \\
\text { DF (2) } \\
\text { DF (4) }\end{array}$ \\
\hline
\end{tabular}

Em 1970, o êxito dos três parlamentares que tentaram a reeleição indica a estabilidade das carreiras políticas destes ex-perrepistas. Entre os remanescentes deste partido, pode-se, também, constatar a importância dos laços de parentesco para o ingresso e a manutenção de carreiras políticas. Assim como se observou a presença de filhos, sobrinhos e primos das maiores lideranças políticas do estado, a esposa da maior liderança perrepista baiana, Manoel Novais, conquista em três ocasiões uma vaga na Câmara dos Deputados. Sendo a única mulher a figurar nas bancadas arenistas analisadas, Neci Novais inicia sua carreira política elegendo-se deputada federal em 1962. Após filiar-se ao novo partido governista em 1966, Neci Novais reelege-se neste mesmo ano e, em 1970, conquista o seu terceiro mandato na Câmara dos Deputados. No entanto, em 1974 Neci Novais alcançou apenas uma suplência, deixando a Câmara dos Deputados em janeiro do ano seguinte.

\section{Tabola 17}

Trajetória dos deputados arenistas baianos, $P R-1974 / 1978$
\begin{tabular}{l|l|l|l|l|} 
Deputado & Migração & "Investimento" & $N^{\circ}$ cargos & Cargos anteriores \\
$\begin{array}{l}\text { Manoel Novais } \\
\text { Teódulo de Albuquerque }\end{array}$ & 1 & $33 / 37$ anos & 2 & ChdeGabeDF $(9) /(10)$ \\
DF $(5) /(6)$
\end{tabular}

Fonte: Abreu et al. (2001) 
Sendo confirmados em longas trajetórias, os remanescentes do antigo PR baiano são dois exemplos do alto grau de estabilidade identificado nas carreiras dos deputados federais da ARENA no estado. Ilustrativa deste perfil é a trajetória da maior liderança perrepista, Manoel Novais. Após ter sido chefe-de-gabinete do então interventor baiano Juraci Magalhães entre 1931 e 1933 e ex-deputado federal (1934-1937), Manoel Novais, com o fim do Estado Novo, voltou a se eleger deputado constituinte na legenda udenista em 1945. Foi durante esta legislatura que o parlamentar migrou para o Partido Republicano, partido em que estabeleceu as bases da sua liderança política. Reeleito em 1950, o parlamentar ocupou a vice-liderança do partido na Casa. Conquistando mais um mandato em 1954, além de continuar nesta função, Manoel Novais acumulou também o cargo de vice-líder da minoria na Câmara.

Reeleito novamente em 1958 e 1962, após sua filiação à ARENA, Novais conquista, em 1966, o seu primeiro mandato sob a nova legenda, tornando-se em um dos mais experientes parlamentares arenistas na Casa. Assim como João Alves, Teódulo de Albuquerque, Fernando Magalhães, José Penedo, Odulfo Domingues e Wilson Falcão, Manoel Novais, figura entre os parlamentares arenistas que se mantiveram na Câmara dos Deputados ao longo de todo o período analisado. Após conquistar o seu décimo mandato em 1978, com o fim do bipartidarismo Novais filia-se ao Partido Democrático Social, pelo qual conquistou o seu último mandato (o décimo primeiro) na Casa em 1982.

\section{Inimigos até a véspera:}

a presença de dois ex-pessedistas na bancada baiana

$\mathrm{Na}$ Bahia, a rivalidade existente entre PSD e UDN ao longo de todo o período multipartidário ajuda a explicar o fato de o PSD migrar majoritariamente para o MDB e não para o novo partido governista quando da instauração do bipartidarismo. Dessa forma, ao contrário do que ocorria na maioria dos estados, onde é o PTB o principal formador do partido oposicionista criado em 1966, levando-se em 
consideração a migração dos então deputados federais baianos para os dois novos partidos, observa-se que, dos 10 deputados pessedistas, apenas um filia-se à legenda arenista e nove passam a formar a base de sustentação do MDB no interior da bancada federal baiana na Câmara dos Deputados.

Contudo, ainda é possível identificar dois ex-pedessistas (além de Oliveira Brito) no interior das bancadas eleitas pela ARENA baiana. Mesmo convivendo com seus antigos adversários políticos e sendo minoria dentro do novo partido, este grupo, a exemplo do anterior, caracteriza-se pela grande estabilidade na manutenção dos postos de seus membros na Câmara dos Deputados.

\section{Tabela 18}

Trajetória dos deputados arenistas baianos, PSD- 1966

\begin{tabular}{l|l|l|l|c} 
Deputado & Migração & "Investimento" & N$^{\circ}$ cargos & Cargos anteriores \\
Fernando Magalhães & Não & 8 anos & 1 & DE(2)
\end{tabular}

Fonte: Abreu et al. (2001)

Em 1966, apenas um remanescente do PSD conquista uma vaga entre a bancada federal da ARENA baiana: Fernando Magalhães. O parlamentar inicia a sua carreira política em 1958, elegendose deputado à Assembléia Legislativa do estado. Após alcançar a segunda suplência no pleito seguinte e assumir uma vaga no legislativo baiano, com a instauração do bipartidarismo, o parlamentar filia-se à ARENA. Em sua nova legenda, o ex-pessedista conquista o seu primeiro mandato de deputado federal em 1966, sendo o único remanescente deste partido integrante da bancada arenista baiana.

Após reeleger-se em 1970 e 1974, Fernando Magalhães torna-se presidente do diretório regional do seu partido. Tendo se licenciado para assumir a prefeitura de Salvador em 1977, a convite do então governador Roberto Santos, o parlamentar reelege-se, no último pleito ainda sob o bipartidarismo, para mais um mandato na Câmara dos Deputados. Após filiar-se ao PDS em 1979, Fernando Magalhães não conquista o que seria o seu quinto mandato, deixando a Câmara dos Deputados em 1983. 


\section{TÉbla 19}

\section{Trajetória dos deputados arenistas baianos, PSD-1966}

\begin{tabular}{|c|c|c|c|c|}
\hline Deputado & Migração & "Investimento" & $\mathrm{N}^{0}$ cargos & Cargos anteriores \\
\hline $\begin{array}{l}\text { Fernando Magalhães } \\
\text { Djalma Bessa }\end{array}$ & $\begin{array}{l}\text { Não } \\
1\end{array}$ & $\begin{array}{l}12 / 16 / 20 \text { anos } \\
16 / 20 / 24 \text { anos }\end{array}$ & $\begin{array}{l}2 \\
1 / 2 / 2\end{array}$ & $\begin{array}{l}\mathrm{DE}(2) \mathrm{eDF} / \mathrm{DF}(2) / \mathrm{DF}(3) \\
\mathrm{DE}(3) / \mathrm{DE}(3) \mathrm{eDF} / \mathrm{DF}(2)\end{array}$ \\
\hline
\end{tabular}

Fonte: Abreuet al. (2001)

O segundo ex-pessedista, Djalma Bessa, inicia sua carreira política candidatando-se a deputado estadual pelo antigo PTB em 1954, conquistando apenas uma suplência. Após filiar-se ao PSD, em 1958 Bessa conquista o seu primeiro mandato no legislativo estadual baiano. Reeleito em 1962, o parlamentar destaca-se na Assembléia Legislativa baiana como líder da oposição ao então governador, o petebista Antônio Lomanto Júnior (1963-1967). Com a extinção dos partidos políticos e a instauração do bipartidarismo, o parlamentar ingressa no partido governista, pelo qual reelege-se em 1966 para mais um mandato como deputado estadual, legislatura na qual o parlamentar, opositor até a véspera da coalizão governamental baiana (a mesma que forma a ARENA no estado), foi escolhido pelo seu novo partido para ocupar a vicepresidência da Casa. Após estrear na Câmara dos Deputados ao ser eleito em 1970, Djalma conquista o seu segundo mandato em 1974, legislatura na qual o parlamentar ocupou a vice-liderança do partido. Reeleito novamente em 1978, com a extinção do bipartidarismo, Djalma filia-se ao PDS, partido pelo qual reelegeu-se mais uma vez no pleito de novembro de 1982.

Com relação à presença dos ex-pessedistas nas bancadas arenistas baianas eleitas à Câmara dos Deputados, observa-se que, se por um lado a presença de poucos remanescentes deste partido tende a reforçar a tese da transposição das rivalidades entre pessedistas e udenistas durante o período anterior nas duas novas agremiações partidárias, o fato destes dois remanescentes do PSD não só acumularem contínuos êxitos eleitorais pela legenda governista, mas também passarem a ocupar importantes espaços no interior do partido é, por outro lado, um indicador da possibilidade do convívio sob uma mesma legenda de políticos que, até a véspera, eram rivais no estado, contrariando o padrão até então identificado. 


\section{Considerações finais: a consolidação da liderança de Antônio Carlos Magalhães e divisão e reagrupamento das antigas correntes arenistas no estado}

Ao longo deste artigo, verificou-se que a ARENA baiana, além de possuir bancadas federais formadas basicamente por parlamentares experientes e com trajetórias prévias relativamente longas, possui uma dinâmica interna pautada pelo predomínio de suas principais lideranças. Esta análise identificou a presença de cinco lideranças que encabeçaram as principais alas do partido no estado. 10

Levando-se em consideração o peso das principais alas da ARENA baiana, o objetivo desta última seção é identificar, a partir do fim do bipartidarismo, o destino de cada uma destas lideranças e suas correntes políticas durante a primeira metade dos anos 80 s. Para isso, além da migração partidária, será analisado o peso de cada partido no interior das bancadas eleitas por este estado para a Câmara dos Deputados, bem como os resultados eleitorais para o governo estadual, em 1982 e 1986.

\begin{tabular}{|c|c|c|}
\hline \multicolumn{3}{|c|}{ Tabela 20} \\
\hline \multicolumn{3}{|c|}{$\begin{array}{l}\text { Representação partidária na } \\
\text { Câmara dos Deputados - BA - 1982/1986 }\end{array}$} \\
\hline & 1982 & 1986 \\
\hline PDS & $64,1(25)$ & - \\
\hline PMDB & $35,9(14)$ & $56,41(22)$ \\
\hline PFL & - & $35,9(14)$ \\
\hline PC do B & - & $2,56(1)$ \\
\hline РCB & - & $5,13(2)$ \\
\hline TOTAL & $100(39)$ & $100(39)$ \\
\hline \multicolumn{3}{|c|}{ Fonte: Camargo e Cardoso, 1997.} \\
\hline
\end{tabular}

${ }^{10}$ Antônio Carlos Magalhães, Roberto Santos, Lomanto Júnior, Luís Viana Filho/ Neto e Juraci/Jutai Magalhães. 
Examinando-se o peso de cada um dos partidos que obtiveram pelo menos uma das cadeiras baianas em disputa, verifica-se que o sistema partidário baiano continua praticamente bipolarizado (1982 PDS x PMDB - e 1986 - PFL x PMDB). Camargo e Cardoso (1997) comentam resumidamente alguns dos dados que mais chamam a atenção ao se comparar o desempenho dos partidos entre as eleições:

\begin{abstract}
Na essência, a lógica eleitoral revelou ainda a predominância de um bipartidarismo de fato. Comparando as eleições de 1986 com as de 1982, verificamos um grande crescimento do PMDB, devido sobretudo ao êxito do Plano Cruzado, implantado pouco antes das eleições, e que levou o PMDB a conquistar a maioria dos cargos majoritários e proporcionais em todo o país. O PFL, nascido do PDS em 1985, surgiu como uma grande força eleitoral, obtendo cerca de $30 \%$ dos votos para a Câmara e para a Assembléia. Já o PDS perdeu completamente sua força eleitoral e não conseguiu eleger nenhum deputado (CAMARGO; CARDOSO, 1997, p.117-118).
\end{abstract}

O êxito inicial do plano cruzado, apesar de ser uma variável fundamental para explicar o desempenho eleitoral do PMDB em 1986, não pode ser tomado como a única causa deste desempenho. Da mesma forma, não ajuda a explicar, por exemplo, o fracasso eleitoral do PDS baiano. Para entender o acentuado declínio do PDS, bem como para ajudar a explicar o crescimento eleitoral do PMDB neste pleito, a trajetória das principais lideranças baianas conta-se também como variável relevante.

Com o fim do bipartidarismo, a fragmentação da ARENA baiana não ocorre de imediato. Em virtude, provavelmente, da grande importância que significa para as cinco principais correntes arenistas identificadas em 1979 o acesso à máquina estadual, apenas a corrente do ex-governador Roberto Santos - que estava isolada apos 1978 deixa o partido. Descontente em virtude da eleição de Antônio Carlos Magalhães no ano anterior para o governo estadual, Roberto Santos desfilia-se do PDS para ser o principal organizador do PP no estado. Com a fusão deste partido e do PMDB, em 1982 Roberto Santos foi escolhido para ser o candidato do partido ao governo estadual.

No PDS, neste mesmo pleito, as quatro correntes disputam a indicação para a candidatura ao governo. Confirmando a força de sua 
liderança, Antônio Carlos Magalhães consegue eleger seu sucessor João Durval Carneiro, contando com o apoio de Luís Viana Neto, que se reelege senador. Com relação às duas outras lideranças, Leur Lomanto chega a lançar seu nome como pré-candidato, desistindo antes da convenção, e Jutaí Magalhães, por sua vez, enfrenta João Durval Carneiro, perdendo a disputa nas prévias do partido.

Após a primeira eleição direta para o governo estadual, a posição das lideranças baianas passa a sofrer uma série de modificações entre 1985 e 1986. A vitória de Paulo Maluf na convenção do PDS para a escolha do candidato do partido à eleição indireta para a Presidência da República, derrotando o então ministro Mário Andreazza11, e a posterior fundação do PFL (Partido da Frente Liberal) foram responsáveis por uma rearticulação significativa de forças na política baiana. Entre as principais lideranças, Jutaí Magalhães (1985) e Leur Lomanto (1986) são os primeiros a deixar o PDS.12

$\mathrm{O}$ fato de estas lideranças terem apoiado Paulo Maluf e, mesmo assim, terem migrado para o PFL indica que a motivação para o ingresso no novo partido tinha suas origens vinculadas mais às rivalidades internas ao PDS, controlado por Antônio Carlos Magalhães. $\mathrm{O}$ fato de as duas lideranças dissidentes terem sido, justamente, as que saíram derrotadas das prévias do partido em 1982 indica a perda de espaço destas lideranças dentro do partido, o que ajuda a explicar a ida para o PFL.

Após um período de indefinição, em que foi cogitada inclusive a possibilidade de criação de um novo partido por Antônio Carlos Magalhães, a maior liderança política do estado (cuja permanência no PDS era dada como improvável desde a vitória de Paulo Maluf) desvincula-se do partido e migra para o PFL. Este processo foi bastante delicado, portanto esta filiação encontrou fortes resistências no diretório do partido no estado. Em Abreu et al. (2001), a descrição do conturbado processo de incorporação da ala carlista ao PFL dá uma idéia precisa das rivalidades entre as antigas lideranças arenistas:

\footnotetext{
"Esta foi em uma das principais derrotas políticas de Antônio Carlos Magalhães, defensor da candidatura Andreazza.

${ }_{12}$ Mesmo tendo ambos votado em Paulo Maluf no colégio eleitoral.
} 
A negociação esbarrou em resistências baianas: seis dos onze membros da comissão provisória regional se opuseram à sua entrada no PFL, frisando que se tratava de um "veto irremovível". O ingresso, porém, já estava acertado com o presidente do PFL, que não podia abrir mão de um grupo integrado pelo governador do estado, um ministro, um senador, nove deputados federais, quatorze deputados estaduais, mais de trezentos prefeitos [...] constituindo, portanto, força amplamente majoritária na Bahia. (ABREU et al., 2001, p.3435).

A ida de Antônio Carlos Magalhães para o PFL (formalizada no dia 7 de janeiro de 1986) acaba provocando a desfiliação de Jutaí Magalhães, Luís Viana Filho e Luís Viana Neto, que ingressam no PMDB, provocando, novamente, a união de três das principais correntes arenistas sob uma mesma legenda partidária (uma necessidade para fazer frente à força eleitoral do PFL no estado). Finalmente, após anos de discordâncias, Lomanto Júnior reaproxima-se de Antônio Carlos Magalhães, filiando-se ao PFL.

Neste cenário, os partidos se lançam à sucessão estadual com os seguintes candidatos: Josafá Marinho e Lomanto Júnior, respectivamente, para governador e senador pelo PFL, e Valdir Pires (emedebista e líder do antigo PSD baiano) e Jutaí Magalhães, candidatos ao governo do estado e ao Senado Federal, pelo PMDB. Com a eleição de Valdir Pires e de Jutaí Magalhães, o PFL acaba ficando quatro anos fora do governo estadual. Um PMDB “inchado" pela adesão de Roberto Santos, Jutay Magalhães, Luís Viana Filho e Luís Viana Neto e beneficiado por controlar o governo federal, e pelo êxito eleitoral do Plano Cruzado: estas são as principais características que explicam o êxito eleitoral do partido nas eleições estaduais de 1986.

Mesmo assim, o peso da liderança de Antônio Carlos Magalhães mantém-se e, em 1990, candidatando-se (pela terceira vez) ao governo estadual, o então ministro de estado conquista mais uma vez o executivo baiano. "Contando com o apoio de cerca de dois terços dos 415 prefeitos baianos, elegeu-se em outubro, derrotando por uma ampla margem de votos Roberto Santos, candidato situacionista" (ABREU et al., 2001, p.3438). 
Analisando-se a trajetória das lideranças arenistas baianas, observa-se que a presença da ala liderada por Antônio Carlos Magalhães não deixou muitos espaços no interior do PDS baiano para as demais lideranças, que acabaram deixando, paulatinamente, o partido para acomodarem-se no interior do PMDB e do PFL. No entanto, mesmo após assumir o controle isolado do PDS baiano, Antônio Carlos Magalhães acaba por deixar o partido no início de 1986, provocando o esvaziamento do PDS no estado, que ajuda a entender o desempenho do partido em 1986.

Para compreender a saída de Antônio Carlos Magalhães do partido, é preciso atentar para o fato de que, além da derrota política sofrida pelo ex-governador, provocada pela vitória de Maluf sobre Andreazza, o PDS em 1986 não representava um caminho seguro para se chegar ao governo estadual. Além deste aspecto, o fato da vitória de Tancredo Neves no Colégio Eleitoral representava o afastamento do partido e da máquina federal. Neste contexto, longe da máquina federal e estadual, a passagem para o PFL representaria a manutenção do acesso a estes bens seletivos, fundamentais para a manutenção da sua liderança.

Levando-se em consideração o que foi aqui visto, conclui-se que, sob a capa do partido oficial, agrupavam-se várias correntes internas não só bastante diferenciadas entre si, mas também em constante disputa pelo controle do partido e dos principais postos de governo. Nesse sentido, a partir da identificação da importância que as lideranças arenistas tiveram no interior do partido, constata-se que a ARENA baiana era profundamente dividida em seu interior. Paralelamente a este aspecto, seus parlamentares possuem um perfil marcado por longas trajetórias políticas prévias.

Filiação partidária e vinculação a um determinado chefe político: estas são duas das principais variáveis identificadas para que se possa mensurar o grau de coesão partidária das bancadas arenistas na Câmara dos Deputados. Por um lado, a análise da trajetória dos parlamentares arenistas indica a existência de um grau considerável de coesão partidária. Por outro, a identificação da importância exercida pelas principais lideranças arenistas aponta para a existência de facções claramente definidas no interior do partido. 
Este é, talvez, o maior paradoxo encontrado na análise da legenda arenista baiana. Além das clivagens representadas pela origem partidária, o fato de pertencer a uma determinada facção constitui-se em variável relevante para a compreensão do caso baiano, o que revela a sobreposição de clivagens no interior da ARENA no estado.

Nesse processo, o fato de as diferentes facções serem formadas por quadros marcados por laços estáveis com suas lideranças, reforçados ao longo de anos de convivência tanto nos partidos políticos anteriores (1945-1965) como ao longo dos 15 anos de existência da ARENA, o fato, retorna-se,verificado no exame da trajetória dos deputados federais, é fundamental para compreender o realinhamento partidário neste estado com o advento da Nova República.

Uma ARENA dividida internamente entre suas principais lideranças partidárias, mas com grupos internos extremamente unidos ao redor de suas respectivas lideranças, este é o retrato da legenda do regime na Bahia. Esta é a chave para explicar o seu desmembramento com o advento da Nova República.

\section{Referências}

ABREU, Alzira et al. (Coords). Dicionário Histórico-Biografico Brasileiro pós-1930. Rio de Janeiro: FGV; 2001.

CAMARGOS, Malco B.'; CARDOSO, Maria das D. Bahia: formato e funcionamento do sistema partidário. In: JUNIOR, Olavo B. (Org.). O Sistema Partidário Brasileiro: diversidade e tendências - 1982-94. Rio de Janeiro: FGV, 1997.

FIGUEIREDO, Argelina; LIMONGI, Fernando. Executivo e legislativo na nova ordem constitucional. São Paulo: FGV, 1999.

FLEISCHER, David. Os Partidos Políticos no Brasil. Brasília: UnB, 1981. v.1.

KINZO, Maria D' Alva G. Oposição e Autoritarismo: gênese e trajetória do MDB. São Paulo: Idesp, 1988.

LIMA JUNIOR, Olavo B. (Org). O sistema partidário brasileiro: diversidade e tendencias, 1982/1994. Rio de Janeiro: FGV, 1997. 
MADEIRA, Rafael Machado. ARENA ou ARENAs? a coesão partidária da legenda do regime em três estados brasileiros. 2002. Dissertação (Mestrado) Ciência Política, UFRGS, Porto Alegre.

MAINWARING, Scott; MENEGUELLO, Rachel; POWER, Timoty. Partidos conservadores no Brasil contemporâneo: quais são, o que defendem, quais são suas bases. São Paulo: Paz e Terra, 2000.

MELHEM, Célia S. Politica de botas amarelas: o MDB-PMDB paulista de 1965 a 1988. São Paulo: Hucitec, 1998.

MENEGUELLO, Rachel. Partidos e Governos no Brasil Contemporâneo (1985 - 1997). São Paulo: Paz e Terra, 1998.

PANEBIANCO, Ângelo. Modelos de Partido: organización y poder en los partidos políticos. Madri: Alianza, 1990.

POWER, Timothy. The political right in postauthorian Brazil: elites, institutions and democratization. Pennsylvania, Pennsylvania State University Press, 2000.

REIS, Fábio W. (Org.). Os Partidos e o regime: a lógica do processo eleitoral brasileiro. São Paulo: Símbolo, 1978.

RODRIGUES, Leôncio M. Partidos, ideologia e composição social: um estudo das bancadas partidárias na Câmara dos Deputados. São Paulo: Universidade de São Paulo, 2002.

SAMPAIO, Nelson de S. Perfil eleitoral da Bahia - 1966. Revista Brasileira de Estudos Politicos. Belo Horizonte, n.23/24, jul.1967/jan.1968.

SAMPAIO, Consuelo N. Partidos Politicos da Bahia na Primeira República: uma política da acomodação. Salvador: Editora da Universidade Federal da Bahia, 1998.

SANTOS, André M. Não se fazem mais oligarquias como antigamente: recrutamento parlamentar, experiência política e vínculos partidários entre os deputados brasileiros (1946 - 1998). 2000. Tese (Doutorado) - Ciência Política, UFGRS, Porto Alegre.

SANTOS, Fabiano (Org). O poder legislativo nos estados: diversidade e convergência. São Paulo: FGV, 2001. 


\section{Abstract}

This paper aims at analyzing the degree of partisan cohesion of ARENA in Bahia, having the investigation of political career patterns of ARENA's federal deputies elected under the two-party system as guideline. In order to measure the degree of cohesion, data referring to Congressmen's party trajectories will be taken as variables. Therefore, aspects such as the number of party migrations, the time of affiliation previous to being elected in the Congress, and the number of offices occupied and mandates held will be taken as parameters for analysis. Finally, this article explains, for example, the fragmentation of the inner structure and composition of ARENA in Bahia, and the subsequent electoral failure of its successor -PDS- after the New Republic by means of the political trajectory of its primary leaders remaining from the pro-government legend.

Key words: political parties; authoritarianism; democracy. 